\title{
A framework on interactions of climate and energy policy instruments
}

\author{
V. Oikonomou $\cdot$ C. J. Jepma
}

Received: 18 May 2006/ Accepted: 22 January 2007/Published online: 15 February 2007

(C) Springer Science+Business Media B.V. 2007

\begin{abstract}
In this paper we analyze the concept of interactions between policy instruments addressing environmental, energy and climate change issues. Although discussion on such policies has been taking place for almost two decades, their interactions are not so sufficiently explored. Initially, we refer to literature on various types of interactions and we classify them. Furthermore, we construct a qualitative method that can assist policymakers in selecting an optimal policy mix. This method breaks down into numerous components, the areas where different policies interact, and facilitates the unveiling of potential overlaps and complementarities. These areas consist of categories as measure identification, objectives, scope, market arrangements, market flexibility, financing, technological parameters, timing, compliance parameters and institutional setup. In addition, it renders the possibility of combining different options and design elements of policies. Furthermore, a list of various criteria serves as an assessment tool for interactions, where a weighing factor and uncertainty parameters have been added, in order to produce an aggregate indicator of the ex-ante analysis of the policy mix selected. Through this method, we present a complete framework of discernment of diverse forms of environmental policy instruments.
\end{abstract}

Keywords Climate policy · Instruments evaluation · Integration options · Policy interaction

\section{Introduction}

Recent trends in climate change, energy efficiency, and renewable energy policies tend to support market-oriented schemes due to their high efficiency and market acceptance. Within the context of United Nations Framework Convention on

\footnotetext{
V. Oikonomou $(\bowtie) \cdot$ C. J. Jepma

SOM, University of Groningen,

PO Box 800, Groningen $9700 \mathrm{AV}$, the Netherlands

e-mail: v.oikonomou@rug.nl
} 
Climate Change (UNFCCC) Kyoto Protocol, several energy and climate policy instruments, i.e., European Union Emissions Trading Scheme (EU ETS), UNFCCC Kyoto Protocol project-based mechanisms, benchmarking, White Certificates (WhC), Tradable Green Certificates (TGC), command-and-control mechanisms and many others, evolve. As these instruments are designed and implemented in an already policy crowded environment, interactions take place. These interactions can take different forms and shapes and in general can be complementary, competitive or self-exclusive. Various interactions of different policies, which target at different areas of economic activities, are likely to result in complementarities and reinforcement among the policy mix. However, there is also a significant risk that different policy instruments might undermine each other's objectives and credibility. This raises the issue of compatibility of different regimes, which is crucial for policy design. In this sense, policy interactions (PI henceforth) can affect the result of overall targets of climate policy either positively or negatively.

In literature so far, few studies have dealt with the issue of climate PI. In most studies, with a notable exception of the Interact project (see Sorrell 2003), the focus lies mainly on comparison of couples of different policy instruments with some attempts of analyzing potential interactions. Nevertheless, in most of these case studies, the methodology is confined to a measure-to-measure analysis (predominantly emissions trading with taxes), but an extrapolation of such comparisons to a general category of policy instruments is not present. Although individual measures and policy instruments are analyzed at a great extent, the basic reasons why their interactions gained little attendance still remain unclear, even if they are recognized as a key issue for policy success. From a research point of view, one possible explanation could be the lack of ex-post experience and thorough evaluations in the long run of most of these policies. Furthermore, high degree of policy uncertainty makes studies in this field rather difficult. Finally, especially in the case of international policies, experience from negotiations (see UNFCCC Kyoto Protocol) has revealed that they are a sensitive issue that reflects global or national political preferences.

The basic objective of this study is twofold: on one hand is the understanding of the essence of PI and the conceptualization of a framework for further analysis. On the other hand, departing from the work of Sorrell (2003) and through combining various literature sources, we adapt and evolve a method of assessing interaction of current and future climate policies, with specific criteria and parameters. This method can be used and further developed for forthcoming evaluation studies on policy combinations, where an extended policy package can be analyzed, rather than the measure-to-measure that is used so far. This method is purely qualitative and provides a useful insight of several aspects of PI. The method is currently enhanced with modeling exercises (see Energy and Climate Policy Interactions (ECPI) model developed by the University of Groningen and National Technical University of Athens), in order to better reflect reality and its application by policy-makers on specific policies.

In Sect. 2 we present a categorization of existing measures according to economic theory and literature. In the following Sect. 3, we present findings from different studies on the background of PI through numerous examples of individual policy instruments. Furthermore, we identify all possible areas of PI in a detailed form and we extract initial bottlenecks and opportunities of combining policy instruments. In Sect. 4, we conduct a thorough literature survey on criteria for policy evaluation and 
through a synthetic approach we construct an elaborated list of these parameters that determine the qualitative or quantitative outcome of PI. We coalesce the elements from Sect. 3 and construct a conceptual model that serves as a tool for further evaluation of PI. Finally, we conclude with some recommendations on bounding off the constrictions stemming from different policy instrument interactions.

\section{Climate change policy instruments}

In this section we present different instruments for climate and energy policy. They are categorized according to their degree of intervention in the market and to whether they target producers (upstream) or users (downstream) of a polluting activity. We acknowledge that such categorization differs within each literature source and therefore we make use of general studies (OECD 1997; IPCC 2001 and others).

Financial measures include subsidies, grants, and taxes. The government can change the cost of energy through taxation and subsidy policies. The latter include grants and low-interest loans while taxation policies address energy use or pollution. The following types of taxation can be distinguished:

- Emission charges/taxes stand for direct payments based on measurements or estimates of quantity and quality of pollutant discharged.

- User charges are payments for the cost of collective service functioning as a financing device by local authorities e.g., for collection and/or treatment of solid waste or sewage water.

- Product charges/taxes are applied to products that create pollution either when they are manufactured, consumed or disposed of. Product charges/taxes are intended to modify relative prices of products and/or finance collection and treatment systems. One practical form of product charges/taxes is tax differentiation leading to more favorable prices for "environmentally friendly" products and vice versa (e.g., car sales differentials as on fuel efficiency, existence of catalytic converter, compliance with emission standards and tax differentiation between leaded and unleaded fuel) (OECD 1997).

Legal or regulatory instruments, where governments can set legal requirements on power companies, industry and households with financial penalties for noncompliance. They are traditional main pillars of environmental policy (commandand-control). Examples include appliance, vehicle and building standards (on energy use or emissions), land and other resource management codes and standards for technology (e.g., a renewable portfolio standard in electricity requires that a minimum percentage of electricity is produced by renewable technologies).

Organizational measures include negotiated and voluntary agreements. They are commitments undertaken by power producers or industries in consultation or negotiation with a public authority and are usually recognized by that agency; they are expected to have a high degree of effectiveness if they are combined with other policies. These agreements can take many forms concerning the degree of bindingness (e.g., legally non-binding press statements to legally binding covenants). They include a wide range of issues, such as a decrease in energy consumption or phasing in of low sulphur petrol. 
Certificates or marketable (tradable) permits/quotas are, among others, emissions trading schemes, White, Green and Combined Heat and Power (CHP) Certificates. For emissions trading schemes, the basic principle is that any increase in emission from a given source must be offset by a decrease in emissions of an equivalent quantity. For example, when a statutory ceiling on pollution levels is fixed for a given area, a polluting firm can set up a new facility or expand its activities only if it does not increase the total pollution load. The firm must therefore buy "rights" or allowances to pollute from other firms located in the same control area, which are then required to abate their emissions by an amount equal to additional pollution emitted by the new activity (OECD 1997).

\subsection{Categorization of instruments based on their absolute targets}

A basic distinction between measures is their ability to steer the absolute level of energy use and emissions: RD\&D (Research, Development and Demonstration) can improve energy efficiency, but the concrete outcome in absolute terms is usually hard to foresee since a substantial share of all RD\&D efforts does not result in a commercial product or service. Grants, loans and tax incentives may be more effective than RD\&D since governments can decide to offer them only for products or services that are particularly energy efficient. Labelling concerns concrete products classified into different categories of energy efficiency and has a greater potential to contribute to lower absolute energy use: if successful, it influences shares of energy efficient purchases and hence contributes to a more efficient product stock. Labeling operates via awareness and relies on well-informed buyers. Standards have a prescriptive character and reduce energy use more directly. Examples of standards on energy use are those implemented for buildings, but in this case total energy is still likely to increase if the number of buildings increases. Negotiated/voluntary agreements relate to one product and service unit and are independent of economic development. There are also negotiated/voluntary agreements that refer to a larger system (e.g., a sector) and concern its energy use in absolute terms or energy-related emissions (defined likewise but less frequently the case). In this case, there is a clear intention to steer the absolute input of energy or the absolute output of emissions. The latter is also true for taxes. The rationale of indirect energy taxes is that the stimulation of energy efficient behavior. If the tax rate is set at a new (higher) level the only way to keep overall expenses the same is to reduce energy use. In contrast, emission trading with fixed caps directly addresses the absolute quantity of emissions but allows for flexibility in goal achievement by means of a certificate system. The categorization of the above-mentioned policy instruments according to their basic characteristics is presented in Fig. 1.

\section{Defining interaction of policy instruments}

In this section we make use of literature studies on combining policy instruments and identify two core characteristics: the general theoretical background in the first part and the specific areas and actors of PI in the second. We compound these elements and construct an initial part of a theoretical model that canvasses the interaction of climate policy instruments. 


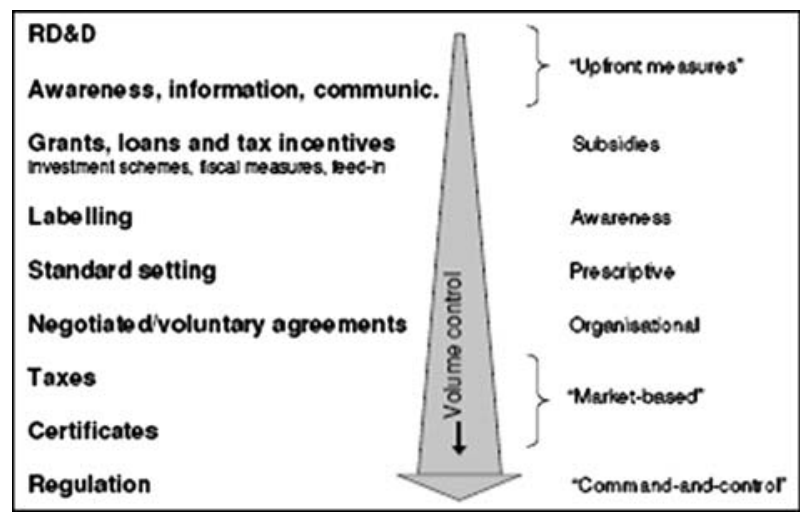

Fig. 1 Policy instruments categorization. Source: adapted from Oikonomou and Patel (2004)

\subsection{Theoretical background of interaction}

In order to thoroughly analyze the effects of a combination of different instruments in climate policy, a proper definition of PI is required. Literature provides a broad range of ideas on setting up a framework on the understanding of interactions. Nevertheless, as mentioned before, most of these studies, with some illuminating exceptions (see Sorrell 2003; Johnstone 2003 and others) refer to combinations or comparisons of couples of different policy instruments, mainly emissions trading schemes with taxes or other existing instruments in the policy mix.

\subsubsection{Studies on general policy mix}

One study on PI is the INTERACT project, which explores relationships between the EU ETS and other climate policy instruments. A basic distinction in this study is the internal and external interaction. The former refers to two or more climate policy instruments while the latter to a climate and a non-climate policy instrument (environmental or energy policy). A typical example is an emission trading scheme and a carbon tax that affects the same participants, while for the second case an emissions trading scheme that targets electricity generators and an energy tax at the point of consumption, irrespective of the carbon content of the energy used (Sorrell and Sijm 2003). Furthermore, an important division in the same study at the level of governance is horizontal and vertical interaction. Horizontal refers to the same level of governance (e.g., EU ETS and EU labeling for energy efficiency appliances) while vertical to different levels (e.g., Renewable Energy Certificate System (RECS) with TGC in one member state). Other types of PI distinguished in this study are: Operational, sequencing and trading. Operational entails the case where two policies coexist when individual target groups may shift from one policy to the other or when obligations set by one policy are modified as a result of another policy. An example is with the EU ETS that allows opt-in and opt-out of targeted sectors under some preconditions, when, in the same time a carbon tax takes place in a member state (Sorrell 2003). Sequencing interaction stands for the case where two policies addressing the same group follow each other in time. An example 
is negotiating agreements with industry that are used as a baseline for the calculation of the allocation of allowances under the EU ETS. Finally, trading interaction signifies the influence of two policies through the exchange of one environmental commodity between them, for instance when credits from Joint Implementation (JI) or Clean Development Mechanism (CDM) projects are exchangeable and tradable within the EU ETS. The same analysis of PI has been conducted in similar studies originating from this project (see Sijm 2003; Sijm and van Dril 2003; Sorrel and Sijm 2003; Sorrell 2003a, b). On the same track, a study on interactions of WhC with EU ETS and TGC is presented by Harrison et al. (2005).

Another study that dealt earlier with the issue of environmental policy combinations is by Gunningham and Sinclair (1998). One category of PI there is inherently complementary interactions, where two instruments coexist, irrespective of the climate or environmental target being addressed. An example is voluntarism with command and control regulation (see Environmental Protection Agency 33/50 program in Guningham and Sinclair 1998). Participants in voluntary schemes may have an incentive to go beyond the command and control baseline, but non-participants still comply with the baseline. A second category is inherently counterproductive instrument combinations, where one instrument diminishes the effectiveness of another in the same policy platform (for instance, in terms of flexibility for emissions abatement options, see technology regulations with economic instruments). Another form is combination where the outcome is context specific, where the effect depends on a particular context (e.g., voluntarism and self-regulation).

Boots et al. (2001) in the Intracert project (http://www.renewable-energy-policy.info/intracert/interception.html) and Boots (2003) analyze interactions of tradable instruments in renewable energy and climate change markets. The basic categories are complete integration, complete separation, specified interaction, each one combined with three different policy levels: national, "green bubble" and international. Complete integration refers to the case where the commodity (certificate) of a Renewable Energy (RE) policy incorporates the value of another commodity, i.e., carbon value in an emissions trading scheme. Complete separation implies that two instruments, even if they are parallel implemented, do not interact at all. Finally, specified interaction pertains to PI under certain conditions, for instance when participants in an emissions trading scheme can also use $\mathrm{RE}$ in order to reduce their emissions by importing certificates from RE projects.

In the same context with the previous study, Oikonomou (2004) in the EU SAVE project "White and Green" (http://www.iiiee.lu.se/whiteandgreen), analyzes the issue of compatibility between WhC, TGC and EU ETS. Three types of interactions are considered: parallel functioning, one-way and double fungibility. Parallel functioning refers to a clear distinction in target setting, which excludes the possibility of integrating different schemes. One-way fungible instruments imply that the commodity (certificates) of a policy can be converted to another commodity of the other scheme and be fully traded (see WhC with EU ETS in Bertoldi et al. 2005). Double fungibility expands the interaction up to the possibility of full exchangeability between the two commodities in both schemes. The same issue of one-way fungibility is explored in detail by Calder and Hough (2001), which deal with potential interaction between emissions trading related policies.

Springer 


\subsubsection{General studies}

Johnstone (2003) assesses the link between tradable permits and other environmental policy instruments, mainly direct regulation, environmental taxes, subsidies and voluntary agreements. PI is instrument specific and one policy can be used for instance as a basis for implementing another (see direct regulation for allocation of tradable permits). An evaluation of emissions trading with the Integrated Pollution Prevention and Control (IPPC) Directive is presented by the European Commission (EC 2002). A more general study by Pizer (1999) focuses on interactions between price and quantity support schemes for climate policy, where cost uncertainty determines the sort of interaction. In the same line, Smith (1999) examines the compatibility of permits with other environmental policy instruments. Glanchant (2001) argues in his study on EU environmental policy that PI are a natural outcome within a policy mix but a certain degree of adaptability must be foreseen, where specific requirements must be fulfilled: flexibility in an environmental policy mix, integration with parallel measures in order to reduce policy uncertainty, horizontal co-ordination between different policy branches and decentralization of policy. Blyth and Lefevre (2004) assessed a different form of PI concerning different climate policy instruments and the effect on energy security. Baron and Bygrave (2002) explore the possibilities of linking national emissions trading schemes with the UNFCCC Kyoto emissions trading scheme through specific parameters of interaction.

There are also studies referring exclusively to interactions of different policies with the EU ETS (Blyth and Bosi 2004; Boemare et al. 2003). Blyth and Bosi identify the options of linking non-EU domestic emissions trading schemes with the EU ETS and focus on implications of such linkages to design parameters of the hybrid schemes. At the same time, Anger (2006) assesses the impacts of linking EU ETS to emerging non-EU schemes under the UNFCCC Kyoto Protocol. Within the EU policy context, Boemare et al. (2003) research the potential interactions between the EU ETS and the framework of negotiated agreements and emissions trading that have developed in France and the United Kingdom (UK). Bohringer et al. (2006) analyze efficiency losses from simultaneous application of an emissions trading scheme and emission taxes.

Another part of literature focuses on the area of PI between TGC and emissions trading schemes. Morthorst (2001) examines the case, where an international TGC scheme can be combined with an emissions trading market under grandfathering and auctioning allowances. Similarly, Jensen and Skytte (2003) focus more on the interactions of these instruments and on the different goal setting, represented as RE production and emissions reduction.

\subsubsection{1st step: Initial type of interaction}

We construct our method of PI analysis based on the literature above. The first step defines clearly the type of PI, since different attributes are assigned for different approaches and subsequently policy targets can be specified. For instance, as stated by the Intergovernmental Panel on Climate Change (IPCC 2001), there are differences between national and international co-ordination between policies (e.g., international laws, or conflicts with international environmental regulations and 
Table 1 Example of defining primarily the type of interaction

\begin{tabular}{llll}
\hline Types of interaction & Policy A & Policy B & Policy A/B \\
\hline National (horizontal) & & \\
International (vertical) & & \\
Same policy context (internal) & & \\
Different policy context (external) & & \\
Operational & \\
Sequencing & \\
Trading & \\
Integration & \\
Separation (stand-alone measures) & \\
One way fungibility & \\
Double fungibility & \\
\hline
\end{tabular}

trade laws). Therefore, a kick-off step consists of a conceptual table that recognizes various PI (Table 1).

The types of interactions may vary depending on the scope and categories of instruments. When attempting for instance to identify the links between a carbon tax and an emissions trading scheme, the issue of fungibility should be skipped, since these instruments are not homogeneous (i.e., trading schemes) and refer to different instrument categories. Identification of possible overlaps provides us with an overview of compatibility of policy instruments selected. Such overlaps reduce the achievement of specific targets and jeopardize an integrated scheme. The first methodological step can be expanded to interactions of more than two policy instruments, which can generate more options and types of interactions. Nevertheless, in this paper we limit ourselves to two instruments in order to avoid an increase of the degree of complexity.

\subsection{Areas of policy interaction}

In this section we cite the literature findings on the areas of PI, which are used in our method. As already mentioned, with some few exceptions (Sorrell 2003a, b), most studies have developed a method for studying measure-to-measure combinations, rather than PI as such. In the second step of our method, we break down the design of instruments in detail and extract conclusions for synergies or conflicts within an integrated scheme.

\subsubsection{Literature on areas of policy interaction}

Sorrell (2003) mention that PI can take place in the whole chain of policy design and cycle: in the instrument that addresses a specific problem, the implementation network (mix of public and private bodies that implement the policy), the target groups (economic actors that are influenced directly or indirectly by the policy), the outcomes and objectives that reflect the intended or unintended effects of policy, and finally the context (stands for the broader economic, political and cultural context in which the policy operates). These design elements are linked by rules and influencing mechanisms. Rules are obligatory guidelines that lead the behavior of directly influenced stakeholders, while influencing mechanisms are means of enforcement of the policy and they provide incentives in order to guide participants' 
behavior. The method followed in the subsequent papers of the Interact project (see for instance Sorrell 2003a, b; Sijm and van Dril 2003; Sorrell and Sijm 2003 etc.) defines areas of interaction in some specific categories. Primarily, the scope of PI refers to sectors, sites, and individual emissions sources (target groups) that are directly or indirectly affected by the policy. Furthermore, the objectives of the instruments are depicted in specific energy, emissions, or other environmental targets and can conflict, overlap, complement or be neutral towards each other. Jensen and Skytte (2003) provide an illustrative example that refers to energy goals of a PI in a certificate and power market. A third area of PI is the operational part of the instruments, which refers to aggregate impacts of the instruments to target groups. These impacts can be content specific and depend on the types of measures. Sijm and van Dril (2003) focus for instance on the impacts of the EU ETS with a benchmarking covenant and identify them on electricity prices, on heat and power generation, and on the use of benchmarking as a basis for allowances allocation of the EU ETS. In general, the operation of two instruments can be counterproductive (e.g., when instruments with high prescription undermine others with lower prescription, i.e., taxes), neutral, duplicative (e.g., mandatory standard of an energy efficient technology with subsidy to retrofit that technology), and complementary. The next phase of PI consists of mechanisms of implementation of designed policies. In this step, administrative obligations imposed on the target group, including the functioning, monitoring, and reporting, as well as the obligations on implementing parties (i.e., verification, accreditation, technical issues, enforcement of non-compliance etc) are identified. Finally, timing of PI is examined. This refers to the introduction of each instrument in the policy mix, potential changes that might take place in the lifecycle of each instrument and the flexibility of instruments in terms of reaction from target groups.

Another category of studies that explore areas of PI with a focus more on the implementation issue can be found in Oikonomou (2004) and Bertoldi et al. (2005). Both authors refer to the case of certificate mechanisms as interacting instruments. The market is framed on the level of obligation, the size of target expected from both policies, and the reference point to be measured. Departing from the common areas with the previous study, as sector coverage, impact period and obliged actors, they rivet on the market creation from a combined scheme. More specifically, market participants are identified as entities that receive the obligation and other entities that can act independently providing necessary liquidity to the market, alongside with the definition of different commodities that are traded. Further, they attempt to assign attributes of commodities traded. The implementing issue arising here is whether different commodities should integrate and be bilaterally or multilaterally traded, determined as one-way or two-way fungibility since according to economic theory, more flexibility guarantees lower abatement costs or obstacles can show up. In the same context, more detailed trading rules are explored, like the value of each certificate/commodity and the possibility for banking or borrowing within the policy timetable. Another area of interaction is the institutional infrastructure and the role of responsible bodies, mainly in the field of implementing organizations, monitoring, and verification.

Other studies pore to the PI between different emissions trading schemes (Haites and Mullins 2001; Blyth and Bosi 2004; Boemare and Quirion 2002; Boemare et al. 2003; Calder and Hough 2001 and Baron and Bygrave 2002). As far as the scope and targets set are concerned, areas of interaction identified are, among others, a 
voluntary or mandatory participation, opt-in/opt-out and phase in/out provisions, and absolute or relative targets. Furthermore, on the operational side, these studies focus on the nature of the commodity (allowance or credit), the denomination factor that allows fungibility between different commodities. On the implementation issue, basic areas of PI are compliance regime that includes penalties and sanctions for effective enforcement, market flexibility with borrowing and banking, and ways of trading allowances. Finally, in the institutional setup, the governance of an integrated scheme refers to different bodies and background legislations, to ex-post or ex-ante monitoring and verification procedures and registry provisions.

\subsubsection{2nd step: Towards an integrated method}

Departing from the studies mentioned in the beginning of this section, we combine elements of PI and formulate the second step of our method. In Table 2, we present an analytical table that includes all possible areas of PI alongside with an example of the EU ETS and how it can interact with the Italian WhC scheme. The interaction of the EU ETS with the UK WhC scheme, named Energy Efficiency Commitment has been thoroughly explored by Sorrell $(2003 a, b)$. The purpose of this example is purely to demonstrate the utility of this table, which can be further used for different types of instruments. We acknowledge that a policymaker's "optimal policy mix" problem consists of more complex options from the inventory of policy instruments (i.e., combination of more than two instruments), but for the sake of simplicity we focus on a double interaction.

In this method we divide the areas of PI in 10 basic categories, each one consisting of specific elements. The categories are: Measure identification, Objectives, Scope, Market arrangements, Market flexibility, Financing, Technological parameters, Timing, Compliance parameters and Institutional setup. Our task is to identify the compatibility issue between the categories. An analysis of these parameters can be found in Oikonomou and Jepma (2006). The first step in Table 2 is to break down different policy instruments into these parameters and assess them in a comparable way. Furthermore, under the assumption that these instruments can interact or integrate, we identify which specific elements can be complementary, overlapping or neutral and then we sketch different options for a common policy. There are many cases where there is a significant uncertainty about the accuracy of these parameters and therefore the basic advantage of this method is that it allows a plethora of options for designing policies. It should be noted in advance that the intention of the authors is not to deliver solutions on the integration but merely to demonstrate how different options can be considered when attempting to analyze the interaction of different schemes.

\section{Assessing policy interaction}

In this section we present the third part of our method, focusing on criteria that can be used in order to conduct a policy evaluation. We compile all criteria from literature and formulate them in a structured way in order to draw conclusions. Furthermore, in the second part of this section we provide some explanations on the assessment procedure. 


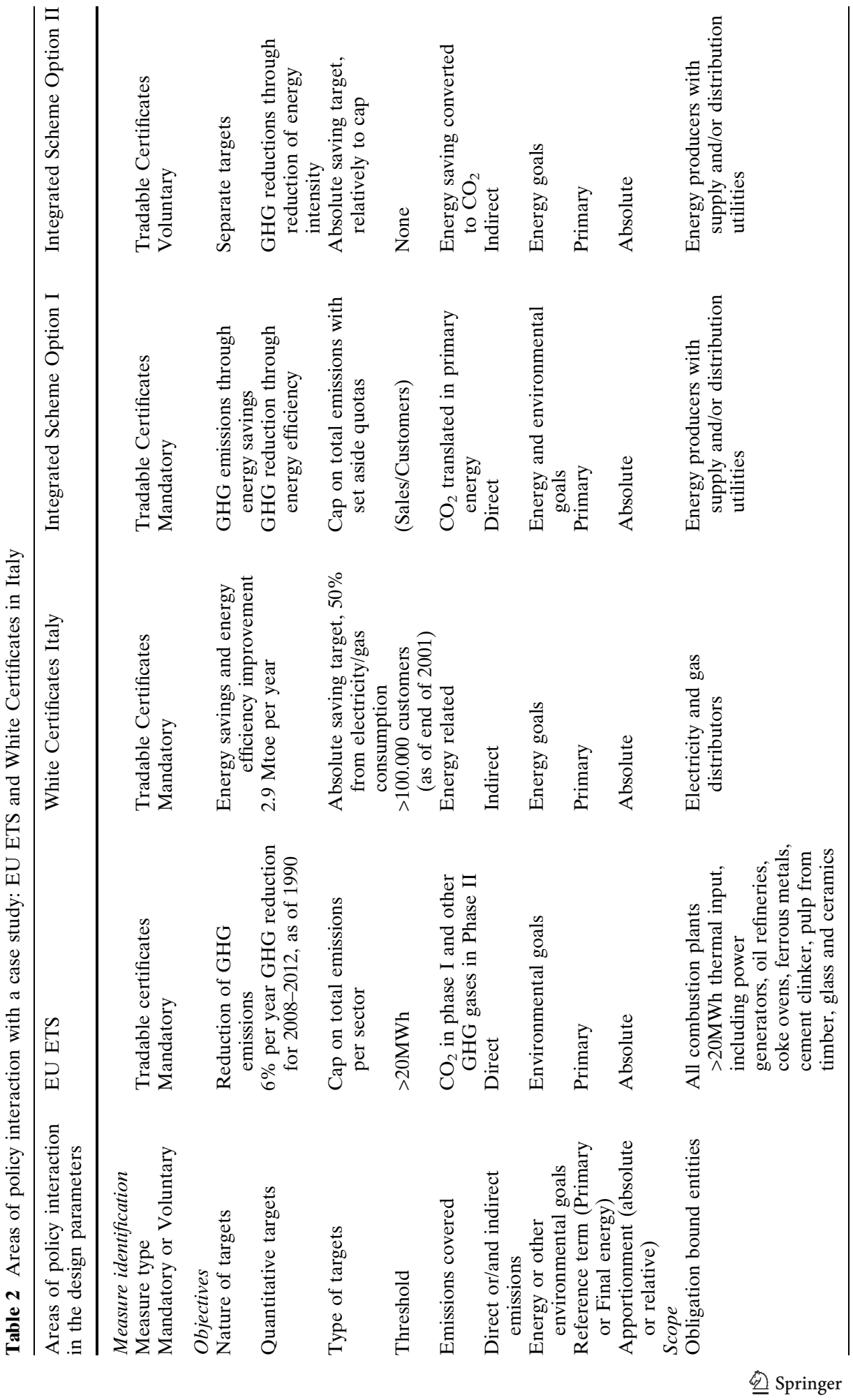




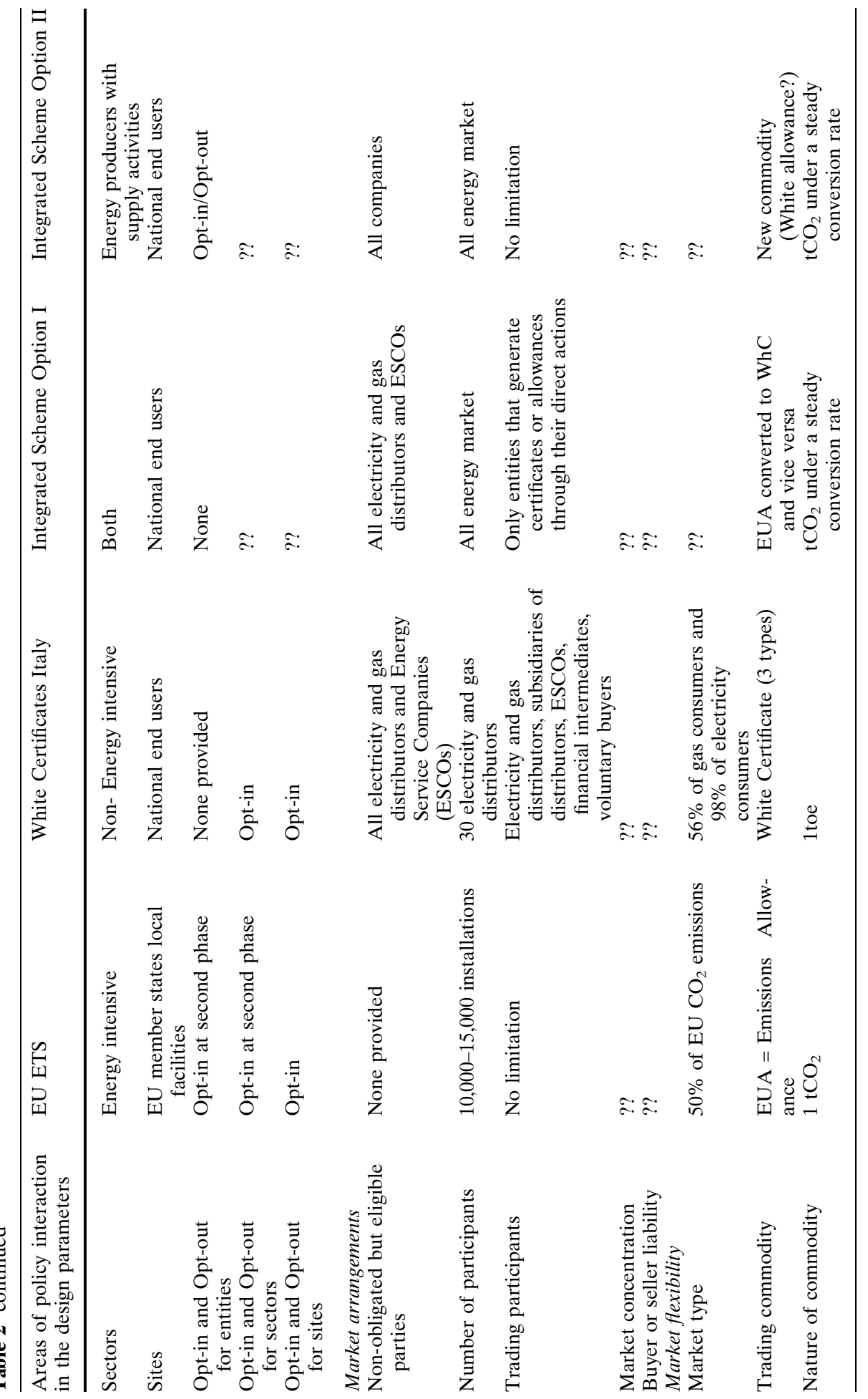




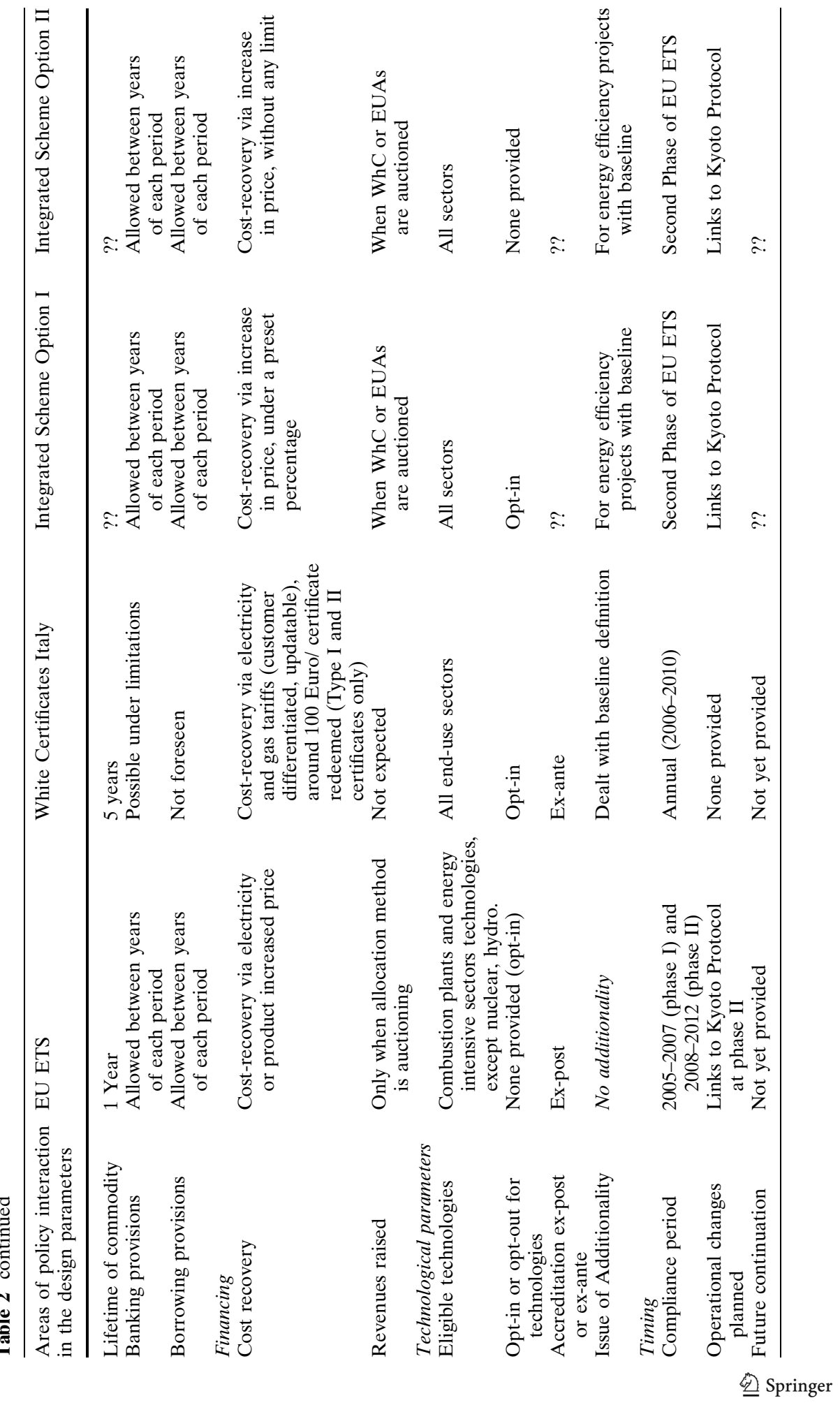




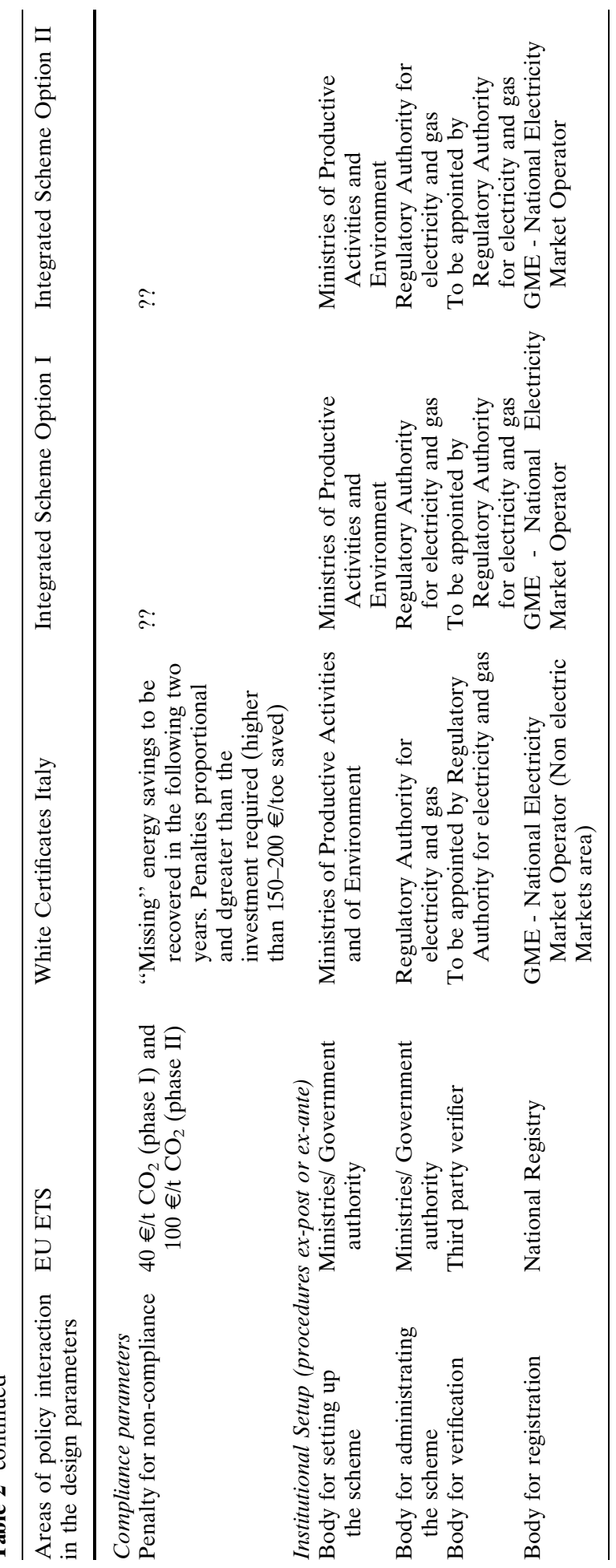

Springer 


\subsection{Criteria for evaluation}

In this section we evaluate the effect that PI has in a broad range of society and economic sectors upon criteria. A policymaker can compare these impacts with the initial policy goals and objectives and weigh them in a general assessment of costs and benefits.

Most studies combine the concept of criteria with areas of PI. In some cases, areas of PI are used as an assessment method, which can complicate the evaluation. We clarify and clearly distinguish among those two. We sort out six general categories of criteria: effectiveness, efficiency, impacts on energy and market prices, impacts on society, innovation, and market competition. A detailed explanation of these categories follows.

\subsubsection{Effectiveness}

As stated by the Organization for Economic Co-operation and Development (OECD 1997), environmental effectiveness depends on the polluters' responses to market signals and is a key issue in evaluating climate policies. A definition of environmental effectiveness by Sorrell (2003) is the likelihood of the policy achieving a specific environmental objective. Andrews (1995) demonstrates that effectiveness is a concept comprised of the assurance of meeting the goals (stakeholders' confidence), pollution prevention, and environmental equity and justice (equality of outcomes and full participation by affected parties in policy decision and implementation). Within the context of PI, this notion expands also to the concept of a potential added value of PI, in comparison to the baseline of stand-alone policy instruments. We take into account the impacts on static and dynamic effectiveness, which implies the fulfillment of PI emission targets with a time scope and also when extending targets through time. We distinguish energy effectiveness, which is substantially different from the environmental and often confounded. Energy effectiveness refers solely to specific energy targets, for instance security of supply or promotion of RE and is not complementary (if not conflicting) to other targets.

Another criterion in this category is environmental integrity, which reflects the impact of PI in the least cost emissions reduction (Haites and Mullins 2001). In addition, security of energy supply is an important parameter in a PI, since most climate policies focus on energy demand or supply sector. Blyth and Lefevre (2004) investigated the impacts of interactions between energy security and climate policies quantitatively on a global scale.

Another couple of parameters for assessing PI refers to the link between targets and types of instruments, through their degree of coercion or prescription (Gunningham and Sinclair 1998; Varone and Aebischer 2001). Coercion refers to the extent, to which external parties or instruments place negative pressure on a firm to improve its performance, while prescription is the extent, to which policy determine the level, type, and method of environmental performance. Although prescription and coercion are descriptive features of a measure or combination of measures, we use them as independent criteria since their degree can influence significantly the cost-effectiveness in a PI.

Finally, we make use of three well-known criteria stemming from market behavior: free-rider effect, Baumol effect, and rebound effect. Free riders are agents that make use of the policy but would have implemented the policy action 
anyway (Train 1994). Blok et al. (2004) provide a methodological approach in quantifying the free-rider effect. Baumol effect can also reduce the effectiveness of a combined policy in the sense that agents participating in a policy (e.g., subsidy) can make partial use of this in order to stimulate other activities (e.g., increase in production), which neutralizes the overall effect of policies. This effect was initially described by Baumol and Oates (1988). Finally, rebound effect basically refers to energy efficiency policies and can be explained from the following causal chain: an increase in energy efficiency lowers the marginal costs of using an energy service. Energy services could be defined as a demanded commodity, i.e., hot water, refrigeration, heat etc. In order to produce this commodity, energy is needed, alongside with other production factors, such as capital, labor and management. Therefore, a utility maximizing consumer increases use of the energy service, which raises the energy demanded (Quirion 2004). An overview of the rebound effect can be found in Binswanger (2001), Greening et al. (2000) and Oikonomou (2004).

\subsubsection{Efficiency}

Efficiency assesses the extent, to which interacting instruments achieve a cost-minimizing pattern of pollution abatement and can be calculated through the relative direct costs and benefits of these instruments (OECD 1997). Sorrell (2003) differentiate between static and dynamic economic efficiency. Static refers to minimization of direct costs of environmental objectives in the short term. In theory, it addresses the overcoming of market failures that imperil the achievement of these objectives (Sorrell and Sijm 2003). Nevertheless, as Russell and Powell (1999) demonstrate, instruments that attain static efficiency can carry over high institutional demands. Dynamic efficiency, on the other hand, implies the potential to promote technological innovation and a reduction in compliance costs in the long run, when new objectives are set (Andrews 1995). Direct costs for obligated parties (i.e., companies) are reflect abatement equipment and use of more costly production techniques (OECD 1997). These direct costs relative to abatement efforts on a regulated market constitute a dimension of efficiency that refers to partial market effects of environmental policies. They can be compared to indirect costs related to economic adjustment effects on other markets through price/cost effects. These effects comprise partially welfare effects of policy instruments, which are treated as a separate criterion, under social effects.

Another category of costs is administration and compliance costs. Administration costs are undertaken from the policy designing authority in a PI, such as information gathering (alias information costs), monitoring, verification, registration, and enforcement costs. Compliance costs are administrative and managerial expenses (different from the direct, as explained above) undertaken by the obligated party in order to comply with the policy. One specific subcategory of compliance costs are transaction costs, which involve expenses required to be undertaken from the target group in order to follow the whole policy chain (e.g., information, technologies, prices, expertise, auditing, reporting emissions, service fees, certification etc). As a general rule, the more procedures involved in the policy chain, the higher these costs. Furthermore, institutional compatibility is linked to direct and indirect costs but is treated here separately due to its high significance for policy makers.

篮 Springer 
Two issues that often come across when evaluating PI are the double regulation and double counting. Double regulation implies a situation, in which one target group is affected directly by two different climate policy instruments that achieve similar objectives. In this case, if targets are not crystal clear, for example they do not address different market failures, obligated entities consider themselves as paying twice for the same target (Sorrell 2003a, b). Double counting is considered one eventual threat to PI and has been often raised as an issue in previous linking between trading schemes (i.e., TGC with the EU ETS, or between the EU ETS and JI/CDM, see EC 2003a; Jepma 2003; Dewees 2001, Lefevere 2003). Double counting of credits or allowances for emissions reduction occurs when the targets for the same amount of emissions from sectors or sites are assigned to different obligated parties (Sorrell 2003a, b). Zapfel and Vainio (2002) provide an illustrative example, where three different effects of double counting are distinguished: double coverage, double crediting and double slippage. Double coverage takes place when two countries implement an upstream and downstream scheme respectively (for instance, when fossil fuel producers in the upstream scheme acquire and trade allowances according to their fuel and consumers or energy users in the downstream scheme must justify their emissions from usage with allowances). In this case, allowances are required twice in order to address the same quantity of emissions. Double crediting occurs when two allowances are generated from one single action of emissions abatement. This case applies to the same upstream/downstream scheme, when for instance the energy users reduce their requested amount of energy (exogenous change) therefore reducing their demand for allowances with a consequence that fossil fuel producers reduce also their production (as a result of smaller demand) and in this manner they free up allowances. The same bottleneck comes along when a downstream emissions trading scheme in a country interacts with a new domestic upstream emissions trading scheme. Double slippage refers to the case when emissions are not covered at all by any scheme. As an example, a country with a downstream scheme exports electricity to a country with an upstream trading, which leads to an increase of non-accountable emissions in the exporting country (since end users are obligated parties) and also an increase in emissions in importing country (since fossil fuel producers are only accountable). Nevertheless, this case is not suitable for the EU since under the EU ETS harmonization has been achieved (Zapfel and Vainio 2002).

Finally, efficiency of the PI can be affected by exogenous changes, where the determining criterion is flexibility and adaptability of the system.

\subsubsection{Impacts on energy and market prices}

In this category we present energy prices as an endogenous variable that can be affected by the PI, opposite to what was presented above, where these exogenous parameters can influence the policy outcome. Our focus lies mainly on the impact on prices of Carbon Dioxide $\left(\mathrm{CO}_{2}\right)$, which can be derived from the price of emissions allowances in the emissions trading schemes. An important factor is the influence on the price of electricity, gas, $R E$ and heat in all stages of their production and sale. Finally, depending on the market structure, an estimation of the impacts of PI on final price of products is necessary in order to derive the loss or gain of social welfare. 
Table 3 Criteria for assessing the impacts of PI

\begin{tabular}{|c|c|c|c|c|c|}
\hline $\begin{array}{l}\text { Criteria for assessing impacts } \\
\text { of policy interaction }\end{array}$ & - & 0 & + & $\begin{array}{l}\text { Weighing } \\
\text { factor }\end{array}$ & $\begin{array}{l}\text { Degree of } \\
\text { uncertainty }\end{array}$ \\
\hline
\end{tabular}

Effectiveness

Static effectiveness

Dynamic effectiveness

Environmental integrity

Energy effectiveness

Security of supply

Degree of coercion

Degree of prescription

Free-rider effect

Baumol effect

Rebound effect

Efficiency

Static efficiency

Dynamic efficiency

Double counting

- Double coverage

- Double slippage

- Double crediting

Double regulation

Compliance costs

Administration costs

Transaction costs (search, negotiation, approval, monitoring, insurance)

Information costs

Institutional compatibility

Flexibility and adaptability in exogenous

changes (electricity, gas, heat

prices and supply shocks)

Impacts on energy and market prices

Price of $\mathrm{CO}_{2}$

Price of electricity

Price of gas

Price of RE

Price of heat etc

Price of products

Impacts on society

Equity and fairness for directly affected parties

Equity and fairness for indirectly affected parties (i.e., consumers)

Employment

Business opportunities and trade

Governmental revenues

Increase of environmental awareness

Political acceptability

Perceived fairness

\section{Innovation}

Invention of efficient technologies

Innovation of efficient technologies

Diffusion of new efficient technologies 
Table 3 continued

\begin{tabular}{lllllll}
\hline $\begin{array}{l}\text { Criteria for assessing impacts } \\
\text { of policy interaction }\end{array}$ & - & 0 & + & $\begin{array}{l}\text { Weighing } \\
\text { factor }\end{array}$ & $\begin{array}{l}\text { Degree of } \\
\text { uncertainty }\end{array}$ & $\begin{array}{l}\text { Total } \\
\text { effect }\end{array}$ \\
\hline
\end{tabular}

Diffusion of existing efficient technologies

Market competition

Liberalization of market

Monopolistic/Oligopolistic threats

Market transparency

Entry barriers

Other general attributes

Product market distortions

Tax distortions

\subsubsection{Impacts on society}

The social impacts of PI can be assessed through numerous ways. We identify some a priori parameters that could be also considered as wider economic and "soft" effects (OECD 1997). Under the "polluter pays" principle, issues of equity and fairness for the directly and indirectly affected parties rise, explaining how different policies can affect either the choices or the competitive position of some parties vis-à-vis other similar parties (Andrews 1995). Another aspect of equity provided in this study is that different policies involve tradeoffs between equality of treatment of different participants and equality of outcome. This implies distributional effects and burden sharing between target groups, when the latter contribute evenly to the achievement of the objective and costs incurred on the one hand, and when the rest of economic sectors can free-ride or benefit from the actions of directly affected target groups while they do not contribute to this effort (or most probably the other way around) on the other. One wider indirect target of the climate policy is employment. More specifically, under a PI between instruments with different targets (e.g., TGC for RE production and WhC for energy efficiency), the result eventually could be a stimulation of the employment in both RE and energy efficiency manufacturing sector. The latter depends on the sources' ability to carry over their increased costs to end-users, which in turn determines market demand for the final product and hence demand for employment in these sources (Baron and Bygrave 2002). Directly linked to employment are business opportunities and trade. An example of RE and market based approaches to Greenhouse Gas (GHG) emissions reduction in terms of employment is presented by Sonneborn (2004). With multiple climate instruments, eventually new markets can appear, such as certificates markets, where new players can seek business opportunities, increasing hence the social welfare. Furthermore, depending on the type of instruments applied, PI can generate revenues for the government, which could be redistributed in order to achieve equity among target groups. Finally, a parameter that is frequently used in environmental policy analysis is the increase of environmental awareness, which indirectly leads the behavior of participating entities in a PI towards more climate friendly production and consumption patterns. 


\subsubsection{Innovation}

A basic target of PI is to address market barriers that prevent the purchase and use of new efficient and "cleaner" technologies. One very important parameter for the overall effect of PI is technology innovation. This criterion comprises a part of the dynamic efficiency, as analyzed above, but we include it separately due to the significant impact it has on its own. Departing from the concept of innovation cycle, we identify impacts of a PI on these phases: $R D \& D$ invention, Innovation and Diffusion of new efficient technologies. An additional parameter, depicted by Andrews (1995), is the diffusion of existing efficient technologies. The impact of PI on innovation can be determined from the typology of instruments involved, since for instance economic instruments are more likely to stimulate innovation in comparison to regulations that merely require a given level of compliance (OECD 1997).

\subsubsection{Market competition}

An assessment of the emerging markets as a result of PI consists of criteria that address fairness and competitiveness. A constraint for PI is that instruments in the policy mix should enhance the energy market liberalization (see for instance EC Directives 1996, 1998, 2003b). With the progressive advent of liberalization of energy market and privatisation of state companies, emphasis has shifted toward market regulations that introduce economic corrections addressing collective interests (such as externalities) and long-term objectives, which generally are not taken into due account by market forces in the absence of corrective measures (Oikonomou 2004). Subsequently, an efficient PI must guarantee market transparency, where market players share the same opportunities in trading and receive correct market signals. Market efficiency can be jeopardized from monopolistic or oligopolistic threats, which can lead to an advantageous position of some entities, which can manipulate prices and reduce competitiveness. Also from the part of policy designing authority that prioritizes targets, it should be vouched that no differential treatment takes place among participants in a PI (Sorrell and Sijm 2003). In the same context, since, at least in theory, the increase of participants provides more abatement options and can thus reduce the compliance and marginal abatement costs to all sources, abolishment of barriers for new entrants is important. Nevertheless, as is stated by OECD (1997), while the extent of new entry can be observed, at a small degree calculation of new entry would have taken place had the climate policies not been implemented can be rather difficult.

Furthermore, as Harrison and Radov (2002) state, an important parameter is the effect of PI on product market and eventual distortions it might provoke. This relates to existing or policy induced inefficiencies in product markets. These distortions can affect the extent to which compliance costs can be minimized. Finally, in the same study another evaluation criterion is tax distortions in the market as a result of PI.

\subsubsection{Uncertainty}

An important parameter for PI that affects most of the above-mentioned criteria lies in uncertainty in the policy choices. A key question is the political acceptability and risk of implementing different policies, defined as the acceptability of key groups in the economic system (Sorrell 2003). Guningham and Sinclair (1998) demonstrate

Springer 
that the implementation of instruments with high intervention and ambition levels encounters political rejection. Varone and Aebischer (2001) and Johnstone (2003) present similar results using case studies of different categories of instruments. Furthermore, other uncertainties that might come up are compliance costs and perceived fairness from obligated parties. Finally, Russell and Powell (1999) present a division of a priori risks for the agency and for the regulated parties. As far as the designing authority is concerned, a risk of failure to achieve goals can prevail, alongside with lock-in existing technologies for too long (and lock out viable alternatives) and other possible perverse responses. For regulated parties, the risk of shifting these policies in time can lead to inefficient investments, since their payback period is pre-calculated according to the initial time frame of the PI. Therefore, these parameters constitute an obstacle in the evaluation of PI and as a result are not mentioned as criteria.

As it can be clearly shown, many of the criteria that we analyzed above are mingled with interlinkages and their inclusion as specific parameters can be debated. Nevertheless, for the purpose of this paper and for the clarity of the method, we include them separately since we attempt to extract their individual significance in a PI.

\subsubsection{3d Step: Evaluation criteria and assessment}

In Table 3 we have conducted a synthesis of the criteria for ex-ante assessment of the climate policy mix. Basic categories of criteria are effectiveness of the integrated scheme, efficiency, impacts on energy and market prices, impacts on society, impacts on innovation and finally impacts on market competition. In each of these categories follows a list of specific criteria that can be assessed as positive, neutral or negative for the functioning of the policy. Assessment is conducted on the grounds of a baseline, where policies are stand-alone and do not interact. This baseline differs between measures and is determined by the time setting, other policies that affect individual measures exogenously, and the general economic environment. OECD (1997) provides a list of different methods for the construction of a baseline for environmental policy, which could also be used in this case:

- Trend extrapolation: simple approach assuming that trends existing before the new policies would continue unchanged if both policies (or at least the one) had not been implemented.

- Econometric methods: use of econometric models that link emissions with some economic variables and include a dummy variable that implies the time when the new policy is implemented.

- Linear programming techniques: indicate how the decisions of firms change in response to different constraints, so they refer mainly to optimization models.

- Judgement methods: Describe the baseline in complete absence of policy. Nevertheless, in this case, the outcome is biased on the judgements made.

By constructing the baseline, we identify the deadweight loss of PI (autonomous behavior of agents) and either subtract it from the total effect or set higher standards for policy targets.

Furthermore, we have introduced a weighing factor, which refers to the gravity of each criterion as reported by the basic focus and tradeoffs of the policy goals. This 
factor reflects eventually the opportunity costs that policy makers are willing to undertake when designing policies. In our method, we allow the tradeoff (weighing factor) for each parameter rather than their aggregated categories, aiming thus at increasing flexibility of the policy makers. Such an example is a PI, where a regulatory authority aims at maximizing security of supply (category effectiveness) sacrificing employment opportunities (category impacts on society), while remaining indifferent on the effect of PI on innovation (category innovation). Evaluation criteria are attributed positive or negative values ( -2 to 2 ). A negative value on a negative criterion means that it affects significantly the outcome of PI. A negative value on a positive criterion means that PI is affected negatively. The final calculations on the main categories of criteria (e.g., effectiveness, efficiency) are an average from all the values (positive or negative) of the sub-criteria. The weighing factor therefore does not represent solely the extent of targets tradeoffs. It rather takes on the overall effect of PI, whether it enhances or jeopardizes the general targets.

In the next column, we take into account the degree of uncertainty as an important key factor for PI evaluation. As mentioned above, uncertainty in an exante study can lead to serious fallacies and because of this, we provide some values of these risks in each criterion. The policy analyst can assign different degrees of uncertainty (varying from 0 up to 1 ) in each specific criterion based on his information gap and the non-stochastic relationships of different policy parameters.

Finally, in the last columns we combine the effects with the significance and the degree of uncertainty of each criterion and we come up with the total effect. Theoretically, we determine this effect through multiplying individual effect with the weighing factor of each criterion and the degrees of uncertainty. This calculation is based on the formula:

$\sum \mathrm{TE} i \equiv \sum A_{i} * W_{i} * U_{i}$, where $\mathrm{TE}$ is the total effect of $i$ criteria, $A$ is the positive, negative or neutral assessment, $W$ is the weighing factor with values 0 to 1 and $U$ is the degree of uncertainty with values 0 to 1 . The policy mix with the highest overall score could be considered as optimal, in relevance to the criteria chosen.

\subsection{Discussion on the overall assessment of policy interaction}

Through the use of the previous methodological tables, we can weigh the significance and tradeoffs of different PI implications and we can proceed to the overall assessment of combined policy instruments. Nevertheless, there are some issues that need to be further explained and discussed.

\subsubsection{Ex-post or ex-ante analysis}

A basic assumption so far is that when applying this methodological tool, we possess full information on the parameters of individual policies. Some problems that might arise from this assumption are the non-predicted instrument impacts, unforeseen developments in the implementation of these policies, further adapted design of instruments, and finally additional policies that might take place parallel to the observed policies. In this context, as recognized by OECD (1997), a clear line has to be drawn between ex-ante and ex-post analysis. Ex-ante evaluation is 
more restricted than ex-post evaluation in the sense that it forecasts impacts of a PI against a hypothetical future scenario and evaluates these effects according to fixed criteria. In contrast, an ex-post evaluation employs observations from the past but still requires the construction of a hypothetical scenario without PI. We conduct an ex-ante analysis, because very few climate policies have been implemented so far and the existing ones are still in an infant stage of providing us with significant results. In general, past experiences from specific (or similar) policies (e.g., some forms of energy taxation or past market trading schemes) can be used in order to project their future effect. Concerning the evaluation step, we acknowledge that absence of actual data can restrict the outcome, while an expost method could reflect at a higher extent reality. Due to this, we have added the degree of uncertainty, as analyzed above, which reduces the risk of false prognoses and dynamic changes of external factors in the course of evaluation process. Such uncertainties, as stated by Pizer (1999) are the energy prices, the future compliance costs, the evolution of new technologies, and determining how uncontrolled emissions levels will change in the future. An alternative way of evaluating interactions could be the mirroring of this methodology, which in practice means that a departing point is the setting of targets instead of choice of policy instruments. Policy makers thus can specify their preferences of criteria (i.e., their objectives) and in a reversed way choice of optimal policy instruments can be revealed, so that the design and optimal policy mix is endogenously determined.

\subsubsection{Practical solutions}

Boemare et al. (2003) mention 4 potential issues that arise when attempting PI: (a) double regulation, (b) double counting, (c) differential treatment and equivalence of effort and (d) fungibility problem of trading commodities. Furthermore, there are some points in our method that could be argued about depending on the choice of policy instruments. A concrete example is the PI between a carbon tax and an emissions trading scheme. In this case, evaluation criteria of the PI can be defined and analyzed, but not all areas of PI are comparable. For instance, the emissions trading scheme is based on a tradable permits market that is evaluated separately (e.g., commodity traded, banking, borrowing etc) and there is no common ground for interaction. In order to ease the adaptability of different policy instruments, some practical solutions are proposed (Glanchant 2001):

- Flexible policy solutions in the case of external changes (making use of market mechanisms that allow greater degree of flexibility in abatement options)

- Use of multiple measures in an integrated form (linking different policies and broadening the scope of legislation)

- Improved horizontal coordination between different policy branches (some PI are an externality to differentiated policy goals)

- Decentralization and subsidiarity (decentralized policies are more apt to adjust to exogenous changes, while policy instruments at a national level can incorporate national economic and social characteristics)

- Policy learning and future ex-post evaluations (linking ex-ante with ex-post studies to verify if intended policy goals are being achieved) 


\section{Conclusions and recommendations}

Under the Kyoto Protocol, countries have to implement various policies and measures in order to fulfill their emission reduction obligations. Parallel to this commitment, other national or international policies aiming at various targets take place. As these policies are designed and implemented in an already policy crowded environment, interactions of these measures are taking place. Many studies so far focused on comparison of couples of policy instruments but their interaction during their implementation phase has gained little attendance. In this paper we address the relatively unexplored issue of interactions of different climate policy instruments on a national and international scale.

The basic outcome of this study is the development of a new method that can assess interactions between different policy instruments. This new conceptual tool is primarily qualitative and does not require empirical data. Nevertheless, the aim is to enhance this method with modeling exercises, in order to better reflect reality and its application by policy makers on specific policies.

Initially, we define existing types of PI according to literature and we construct the framework, upon which these interactions take place. This step focuses on defining ex-ante the interactions, which is fundamental in order to proceed to further analysis.

The following footmark consists of the identification of areas, in which interaction takes place. More specifically, through the use of an analytical table, where all levels of policy are listed, we write down all the attributes of each policy measure and eventually present several options of interaction. This table provides a clear insight of the design parameters of each policy and assists the policy analyst in recognizing potential bottlenecks and advantages of implementing several measures in the same policy context, which often undermine ex-ante policy analysis.

The third step of our method deals with the evaluation of desired interaction according to several parameters. In order to do that, we enumerate several criteria, which assess in a detailed form the outcome of PI. In order to discern the evaluation process, we include an option for a weighing factor, assigned to each criterion individually, which can be adjusted by the policy analyst. These factors stand for the gravity of each criterion and reflect opportunity costs that policy makers are willing to undertake when designing the policy. Furthermore, we provide the option for assigning degrees of uncertainty in each specific criterion, hence reducing the risks of an analysis under incomplete information or random shifts in the policy parameters.

Finally, we would like to remind the reader that our attempt is to analyze interactions of climate policy instruments and present all the alternative options of designing hybrid or complex schemes, rather than proposing harmonization between instruments within a policy mix. Through the use of this method for selected mixes of climate and energy policy instruments, suggestions for an efficient design can emerge.

\section{References}

Anger N (2006) Emission Trading Beyond Europe: Linking schemes in a post-Kyoto world. ZEW Discussion Paper No. 06-058, Mannheim, Germany

Springer 
Andrews R (1995) Environmental policy tools. Office of Technology Assessment, Congress of the United States

Baron R, Bygrave S (2002) Towards international emissions trading: design implication for linkages. OECD/International Energy Agency, Paris, France

Baumol WJ, Oates WE (1988) The theory of environmental policy. Cambridge University Press, UK, $309 \mathrm{pp}$

Bertoldi P, Rezessy S, Langniss O, Voogt M (2005) White, Green and Brown certificates: how to make the most of them?. Paper 7203, EC Joint Research Center

Binswanger M (2001) Technological progress and sustainable development:what about the rebound effect?. Ecol Econ 36(1):119-132

Blok K, de Groot H, Luiten E, Rietbergen M (2004) The effectiveness of policy instruments for energy-efficiency improvement in firms: the Dutch experience. Kluwer Academic Publishers, 197 $\mathrm{pp}$

Blyth W, Lefevre N (2004) Energy security and climate change interactions: an assessment framework. OECD/International Energy Agency, Paris, France

Blyth W, Bossi M (2004) Linking non-EU domestic emissions trading schemes with the EU emissions trading scheme. OECD/ International Energy Agency, Paris, France

Boemare C, Quirrion P (2002) Implementing greenhouse gas trading in Europe:lessons from economic literature and international experiences. Ecol Econ 43(3):213-230

Boemare C, Quirrion P, Sorrell S (2003) The evolution of emissions trading in the EU:tensions between national trading schemes and the proposed EU Directive. Climate policy 3S2:105-124

Bohringer C, Koschel H, Moslener U (2006) Efficiency losses from overlapping economic instruments in European Carbon Emissions Regulation. ZEW Discussion Paper No. 06-018, Mannheim, Germany

Boots M (2003) Green certificates and carbon trading in the Netherlands. Energy Policy 31(1):43-50

Boots MG, Schaeffer G, de Zoeten C (2001) The interaction of tradable instruments in renewable energy and climate change markets, ECN-C-01-048, the Netherlands

Calder F, Hough C (2001) Potential interactions between new emissions trading related policies minimizing conflicts, maximizing synergies and maximizing consistent valuation of carbon savings. Energy for Sustainable Development Ltd, UK

Dewees D (2001) Emissions trading: ERCs or allowances?. Land Econ 77(4):513-520

European Commission (EC) (1996) Directive 96/92/EC of the EU Parliament and the Council of 19/ $12 / 1996$ concerning common rules for the internal market on electricity. Official Journal of the European Union, Brussels

European Commission (EC) (1998) Directive 98/30/EC of the EU Parliament and the Council of 22/ 06/1998 concerning common rules for the internal market in natural gas. Official Journal of the European Union, Brussels

European Commission (EC) (2002) Non-paper on synergies between the EC emissions trading proposal and the IPCC Directive, Brussels

European Commission (EC) (2003a) Directive 2003/87/EC of the European Parliament and of the Council establishing a scheme for greenhouse gas emission allowance trading within the Community and amending Council Directive 96/61/EC Official Journal of the European Union, Brussels

European Commission (EC) (2003b) Directive 2003/54/EC of the European Parliament and the Council of 26/6/2003 concerning common rules for the internal market of electricity and repealing Directive 96/92/EC Official Journal of the European Union, Brussels

Glachant M (2001) The need for adaptability in EU environmental policy design and implementation. Eur Environ 11(5):239-249

Greening LA, Greene D, Difiglio C (2000) Energy efficiency and consumption-the rebound effect-a survey. Energy Policy 28(6-7):389-401

Gunningham N, Sinclair D (1998) Designing smart regulation. OECD/International Energy Agency, Paris, France

Haites E, Mullins F (2001) Linking domestic and industry greenhouse gas emissions trading systems. International Emissions Trading Association, Toronto, Canada

Harrison D, Radov D (2002) Evaluation of alternative initial allocation mechanisms in an EU greenhouse gas emissions allowance trading scheme. Report by National Economic Research Associates prepared for DG Environment, European Commission, Brussels

Harrison D, Sorrell S, Klevnas P, Foss A (2005) Interactions of the EU ETS with Green and White Certificate schemes. Report by National Economic Research Associates prepared for DG Environment, European Commission, Brussels 
IPCC (2001) Climate Change 2001: Mitigation. Contribution of Working Group III to the third assessment report of the Intergovernmental Panel of Climate Change

Jensen S, Skytte K (2003) Simultaneous attainment of energy goals by means of green certificates and emissions permits, Energy Policy 31(1):63-71

Jepma C (2003) KP, EU ETS-How much to link? Editor's note, Joint Implementation Quarterly, the Netherlands

Johnstone N (2003) The Use of Tradable Permits in Combination with Other Policy Instruments. Working Party on National Environmental Policy, Document No ENV/EPOC/WPNEP/ (2002)28, OECD, Paris, France

Lefevere J (2003) Linking emissions trading and project-based mechanisms. OECD Global Forum on Sustainable Development Emissions Trading/CATEP Country Forum, Paris, France

Morthorst P (2001) Interactions of a tradable green certificate market with a tradable permits market. Energy Policy 29(5):345-353

Oikonomou V (2004) A qualitative analysis of White, Green Certificates and $\mathrm{EU} \mathrm{CO}_{2}$ allowances, Phase II of the EU SAVE "White and Green" project. Copernicus Institute, NWS-E-2004-112, Utrecht University, the Netherlands

Oikonomou V, Patel M (2004) An inventory of innovative policies and measures for energy efficiency, Phase I of the EU SAVE "White and Green" project. Copernicus Institute, NWS-E2004-113, Utrecht University, the Netherlands

Oikonomou V, Jepma CJ (2006), A qualitative methodology on analyzing climate change and energy policy instruments. University of Groningen, Energy Delta Research Centre (EDReC), Groningen, the Netherlands

OECD (1997) In: Smith Vos (ed) Evaluating economic instruments for environmental policy. Paris, France

Pizer W (1999) Choosing price or quantity controls for greenhouse gases. Climate Change Issues Brief No 17, Resources for the Future, Washington DC

Quirion P (2004), Les Certificats blancs face aux autres instruments de politique publique pour les economies d'energie:Bilan de literature economique et priorites de recherché. Institut Francais de l'Energie, France

Russell CS, Powell PT (1999) Practical considerations and comparison of instruments of environmental policy. In: van den Bergh JCJM (eds) Handbook of environmental and resource economics. Edward Elgar, Cheltenham, pp 352-379

Sijm J (2003) Interactions of the EU Emissions trading Directive with climate policy instruments in the Netherlands. ECN-C-03-096, the Netherlands

Sijm J, van Drill, AWN (2003) The interaction between the EU Emissions trading scheme and other energy policy instruments in the Netherlands. ECN-C-03-060, the Netherlands

Smith S (1999) The compatibility of tradable permits with other environmental policy instruments, Implementing domestic tradable permits for environmental protection. OECD, Paris, France

Sonneborn C (2004) Renewable energy and market based approaches to greenhouse gas reductionOpportunity or obstacle? Energy Policy 32(16):1799-1805

Sorrell S (ed) (2003) Interaction in EU Climate Policy. Project No. EVK2-CT-2000-0067

Sorrell S, Sijm J (2003) Carbon trading in the policy mix. Oxford Rev EconPolicy 19(3):420-437

Sorrell S (2003) Who owns the carbon. Interactions between the EU ETS and the UK RO and EEC Working paper 100, SPRU, UK

Train K (1994) Estimation of Net Savings from energy conservation programs. Energy-Int J 19(4):423-441

Varone F, Aebischer B (2001) Energy Efficiency: the challenges of policy design. Energy Policy 29(8):615-629

Zapfel P, Vainio M (2002) Pathways to European Greenhouse Gas Emissions Trading History and Misconceptions. FEEM Working Paper No. 85.2002, Milano, Italy 